\title{
Interface slip model for reinforced concrete columns strengthened with concrete jacketing
}

Naci Caglar (Main and Corresponding Author)

Sakarya University, Department of Civil Engineering, Engineering Faculty

Sakarya University of Applied Sciences, Department of Civil Engineering, Technology Faculty

54050 Sakarya (Turkey)

caglar@sakarya.edu.tr

\section{Alexander Sichko}

The Ohio State University, Department of Civil, Environmental and Geodetic Engineering

Columbus, $\mathrm{OH}$ (USA)

sichko.3@buckeyemail.osu.edu

\section{Halil Sezen}

The Ohio State University, Department of Civil, Environmental and Geodetic Engineering

Columbus, $\mathrm{OH}$ (USA)

sezen.1@osu.edu

\section{Erkan Bicici}

Artvin Çoruh University, Faculty of Engineering, Department of Civil Engineering, 08100 Artvin, Turkey

The Ohio State University, Department of Civil, Environmental and Geodetic Engineering

Columbus, $\mathrm{OH}$ (USA)

erkanbicici@artvin.edu.tr

\section{Aydin Demir}

Sakarya University, Department of Civil Engineering, Engineering Faculty

54050 Sakarya (Turkey)

aydindemir@sakarya.edu.tr

\section{A. Farhan Farah}

Sakarya University, Institute of Natural Sciences, Civil Engineering

54050 Sakarya (Turkey)

ahmed.farah1@ogr.sakarya.edu.tr

\begin{abstract}
Retrofit and strengthening of columns can be an effective solution to improve the capacity of reinforced concrete (RC) structures when the structural details and strength are insufficient to resist extreme loads. When concrete jacketing is used by enlarging the existing RC column cross section, the main concern is the performance loss between new and old concrete due to potential interface slip. There are three major options to improve slip resistance at the interface including surface roughening, dowels, or both. In this study, these methods are evaluated and parameters are proposed to model the load transfer along the interface between the existing and new concrete. The response of reinforced concrete jacketed columns is simulated using the proposed numerical models. The effectiveness and need for surface roughening, dowels, or their combination are investigated. A slip coefficient is proposed to model the friction between new and old concrete materials based on comparison of the experimental data and numerical simulations.
\end{abstract}

Keywords: Concrete Structures, Column Retrofit, Finite Element Method, Bond Slip.

\section{Introduction}

Retrofit and rebuilding are two potential solutions for reinforced concrete (RC) structures with columns that have insufficient detailing or strength to withstand seismic loads or other extreme events. Demolition and rebuilding can be expensive and time-consuming. Thus, retrofitting and strengthening of columns can be an efficient solution. Column retrofit methods including attachment of external steel elements, concrete jacketing, and fiber-reinforced polymer 
(FRP) applications have been shown to be effective alternatives (Julio et al., 2003; Parvin \& Brighton, 2014; Tsionis et al., 2014; Vardai, 2018) and can yield significant time and cost savings. A multitude of parameters can impact the effectiveness of a retrofit. Factors including existing concrete strength, corrosion and/or other damage level, loading patterns, and environmental conditions are outside of the control of the design engineer. There are many design variables the engineer can control for concrete jacketing including jacket concrete strength and admixtures, reinforcement amount, temporary shoring, jacket thickness, and interface condition between existing and new concrete.

The main objective of this paper is to evaluate and propose parameters to model the load transfer between the existing and new concrete in reinforced concrete jacketed columns. The guiding mechanical principle of the jacketing is to increase the concrete confinement, which impacts the strength, energy dissipation, stiffness, and displacement ductility of the retrofitted section (Caglaret al., 2019). The amount of composite action between the existing and new concrete influences the relative performance of the retrofitted column. It is well understood that the bond strength between the two concrete sections varies when they are not poured at the same time, and as such should be considered when using a concrete jacket retrofit (Santos \& Julio, 2014; Elbakry \& Tarabia, 2016). The use of approaches to do so, namely surface roughening and dowels, add cost, time and complexity to a retrofit. Many studies (e.g., Julio et al., 2003) employ such special preparations to increase the load transfer between the new and old concrete taking place at the interface, as illustrated in Figure 1a. However, without a comparison to an equivalent section with no special preparation or an equivalent monolithic section to compare to, the relative impact or necessity of employing such preparation methods are not clear (Julio et al., 2003).

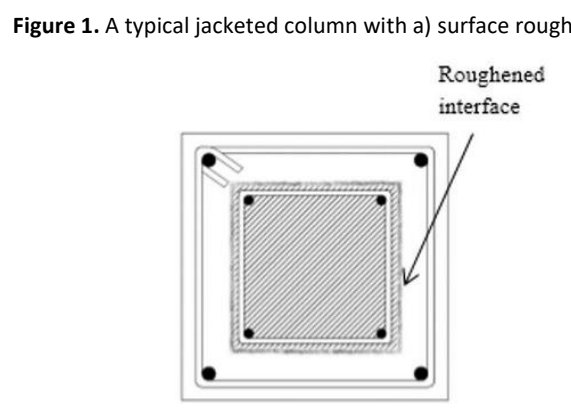

(a)

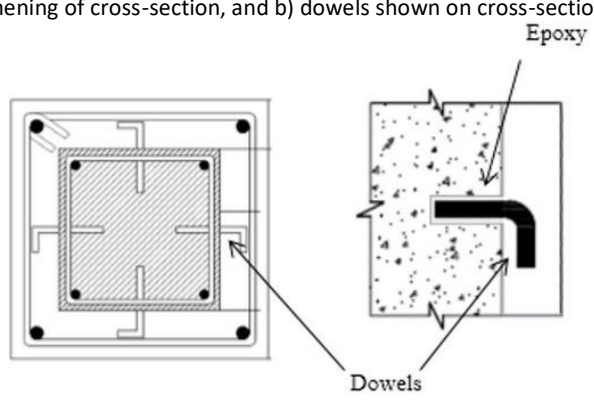

(b)

Use of dowels, surface roughening and their combination are popular methods to increase the load transfer between the new and old concrete (Sichko, 2017; Sichko \& Sezen, 2017). While frequently employed in the field, the actual impact and effectiveness of retrofit design parameters are evaluated using available experimental data and numerical simulations. In this paper, macro models and finite element models are developed, and a new numerical model is proposed to simulate the response of reinforced concrete jacketed columns. The proposed model provides new parameters for slip coefficients to simulate and assess the effectiveness of different retrofit design options and advance the knowledge for the proper design of concrete jacketed columns. This paper aims to improve the understanding of impact and necessity of interface preparation for concrete jacketing of RC columns by compiling and synthesizing the available studies which appropriately document the impact of interface preparation and presenting a new coefficient to model the degree of composite behavior between the old and new concrete.

\section{Methods for Improving the Interface Bond Strength}

The most common methods employed to increase the composite action between the existing column and new concrete jacket are surface roughening, dowels, and their combination, which are considered in this study. There are three useful configurations when the impact of various interface conditions is compared: an original un-retrofitted member, a jacketed member with no special considerations at the interface, and an equivalent monolithic section. Comparison of the jacketed column to the original section provides insight into the efficacy of the retrofit only. Since the goal of this study is to better understand the impact of surface roughening and/or dowels at the interface, it is critical to compare the treated sections to un-treated and monolithic sections. If the behavior of monolithic and jacketed columnsareidentical, this condition represents full composite action and is used as the upper bound for the slip coefficient proposed below. Comparing the jacketed members to one without interface treatment is vital for establishing the need for expensive andtime-consuming methods of surface roughening and dowel installation. This comparison also provides a lower bound for the interface slip coefficient. One of the major objectives of this research is to investigate the effectiveness and need for surface roughening, dowels, or both. 
Surface roughening is one of the main methods for improving the interface bond strength. Fundamentally, increasing the roughness by way of sandblasting, a pneumatic chipping tool or other methodsseeks to increase the friction between the jacket and column, and therefore achieve monolithic behavior, as depicted in Figure 1a. Hacking or chipping the existing column surface has been shown to result in inferior performance and can be undesirable due to the encouragement of micro-cracking of the old concrete (Julio et al., 2003; Kaliyaperumal \& Sengupta, 2009). Additionally, if the column clear cover spalls off, no additional preparation may be required as similar performance to mechanically chipping the surface can be achieved (Rodriguez \& Park, 1994).

There is an agreement in existing research that roughening of existing column surface will result in equivalent to increased amounts of stiffness (Julio et al., 2005; Vandoros \& Dritsos, 2006; Bousias et al., 2007; Julio \& Branco, 2008). Relative to a monolithic section though, the collection of studies reports decreased, equivalent, and increased stiffness. The $15.6 \%$ decrease found by Vandoros \& Dritsos (2006) was the largest of the studies. However, the slight decrease found by Bousias et al. (2007) may be more similar if the monolithic section studied contained the same reinforcement details as the jacketed sections, as in the case of Vandoros \& Dritsos (2006), considering the stiffness contribution of the reinforcement. In general, the retrofitted column stiffness was shown to be slightly less than that of a monolithic section, while still drastically better than the original column stiffness.

Additionally, it is important to note that it was not possible to normalize the results for the degree of surface roughening and that only retrofits where the jacket was at least twice the strength of the original concrete were investigated, potentially not revealing different behavior when the equivalent jacket and core concrete strengths are utilized. If the level of concrete spalling is sufficiently high, it may be possible to achieve the same performance increases by only removing the loose concrete (Rodriguez \& Park, 1994).

The use of dowels involves drilling holes into the existing column and placing pieces of rebar, usually with 90 -degree hooked ends, into the holes anchored by an epoxy, as shown in Figure 1b. The studies (Julio et al., 2005; Vandoros \& Dritsos, 2006; Bousias et al., 2007; Julio \& Branco, 2008; Tsakiris et al., 2012; Vandoros \& Dritsos, 2008) which considered the impact of dowels did not investigate the impact of the various design parameters including dowel spacing, protrusion length, or rebar size; however, all of the investigated parameters were generally within $25 \%$ of each other.

Bousias et al. (2007) reported, using the yield moment as the measure, that utilizing dowels contributed less than $5 \%$ more strength as compared to a column with no dowels and showed less than $5 \%$ reduction in strength as compared to an equivalent monolithic section. In contrast, Vandoros \& Dritsos (2008) found a greater than $50 \%$ increase in yield strength when the behavior of columns with and without dowels are compared. Furthermore, it was found that the presence of dowels resulted in load capacity of within $10 \%$ of a monolithic section. When loaded beyond yield, the performance gap between the section with and without dowels narrows to be within $10 \%$. It should be noted that the core and jacket concrete strength was increase by more than $30 \%$ compared to the column with no treatment and the monolithic section, potentially influencing the results. Across all experiments, a section with dowels was found to have increased performance relative to a jacketed section without dowels, but less than that of an equivalent monolithic section with lower energy dissipation.

The combination of surface roughening and dowels has been shown to result in equivalent or superior performance. This finding is important as engineers who employ the combination of the dowels and surface roughening can reasonably assume nearly monolithic behavior and interpret models accordingly.

\section{Interaction Model}

For design purposes, it is highly desirable to model the behavior of the retrofitted column considering the influence of the slip between old and new concrete. Thermou et al. (2014) proposed a model to quantify this influence on the lateral response of retrofitted columns. The complex analytical steps and assumptions contribute to difficulty in establishing equilibrium between shear stress capacity and demand at the interface for each increment during moment-curvature analysis. To generate a simpler model, this paper proposes to include a slip coefficient to the classic fiber section analysis of an RC column as opposed to determining the shear strength capacity and strength demands at the interface. The slip coefficient $\eta$, representing the amount of cohesion between old and new concrete along with the boundary layer, ranges from a theoretical lower bound value of 0.0 for no cohesion to maximum 1.0 for full composite action. Figure 2 illustrates the effect of interface condition or slip of the composite section for different slip coefficient values.

The slip coefficient values are determined using the experimental data available in the literature, and numericalsimulations. To propose a coefficient to quantify the slippage of jacket concrete, two different numerical 
models are created andanalyzed. Then, the results of numerical models are compared with the experimental data. The details of the experimental data used in this study are reported in Table 1 . In the table, $N$ represents axial load on the specimen, $f_{c}^{\prime}$ is the 28-day compressive strength of concrete, $f_{y}$ and $f_{y w}$ are yield strengths of longitudinal and transverse reinforcement, respectively and $\varnothing$ is diameter of reinforcement. All column specimens had fixed end supports. OpenSees software (McKenna et al., 2004) is used for the macro model and moment-curvature analysis, and ABAQUS (2020) is used for finite element analysis. Julio and Branco (2008), Vandoros \& Dritsos (2008), Bousias et al. (2007), and Rodriquez \& Park (1994) are modeled in OpenSees, while the specimens from Bousias et al. (2007) are also modeled in ABAQUS.

Figure 2. For concrete jacket retrofitted section: a) strain distribution of monolithic section, b) strain variation in section with jacket sliding ( $\eta<1)$, c) concrete stress distribution including jacket slip, d) compressive stresses at larger strains, and e) concrete stresses near failure.

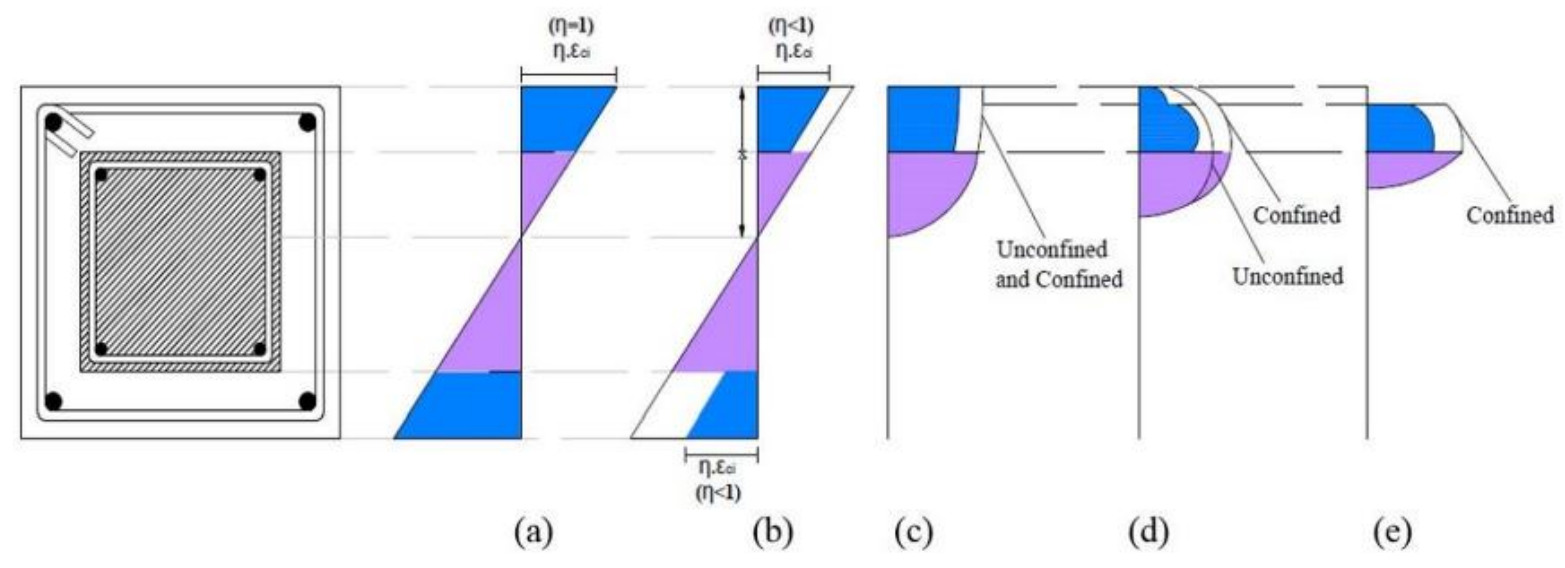

Table 1. Load, material and reinforcement details of the specimens.

\begin{tabular}{|c|c|c|c|c|c|c|c|c|c|c|c|c|}
\hline & \multirow[b]{2}{*}{ Specimen } & \multirow[b]{2}{*}{$N(\mathrm{kN})$} & \multicolumn{5}{|c|}{ Existing } & \multicolumn{5}{|c|}{ Jacket } \\
\hline & & & $\begin{array}{l}\text { Long. } \\
\text { reinf. }\end{array}$ & $\begin{array}{c}\text { Trans. } \\
\text { steel }\end{array}$ & $f_{c}^{\prime}(\mathrm{MPa})$ & $f_{y}(\mathrm{MPa}) f$ & $f_{y w}(\mathrm{MPa})$ & $\begin{array}{l}\text { Long. } \\
\text { reinf. }\end{array}$ & $\begin{array}{c}\text { Trans. } \\
\text { steel }\end{array}$ & $f_{c}^{\prime}(\mathrm{MPa})$ & ${ }_{y}(\mathrm{MPa})$ & ) $f_{y w}(\mathrm{MPa})$ \\
\hline $\mathrm{Q}-\mathrm{RC}$ & \multirow{4}{*}{$\begin{array}{c}\text { Bousias et al., } \\
2007\end{array}$} & 705 & \multirow{4}{*}{$4 \varnothing 14$} & \multirow{4}{*}{$\varnothing 8 / 200$} & 26.30 & \multirow{4}{*}{313} & \multirow{4}{*}{425} & \multirow{4}{*}{$4 \varnothing 20$} & \multirow{4}{*}{$\varnothing 10 / 100$} & 55.3 & \multirow{4}{*}{487} & \multirow{4}{*}{599} \\
\hline Q-RCR & & 795 & & & 27.70 & & & & & 55.3 & & \\
\hline Q-RCD & & 750 & & & 27.40 & & & & & 55.3 & & \\
\hline Q-RCRD & & 800 & & & 26.30 & & & & & 53.2 & & \\
\hline $\mathrm{M} 4$ & \multirow{3}{*}{$\begin{array}{l}\text { Vandoros and } \\
\text { Dritsos, } 2008\end{array}$} & 170 & \multirow{3}{*}{$6 \varnothing 10$} & \multirow{3}{*}{$\varnothing 6 / 150$} & 34.95 & \multirow{3}{*}{520} & \multirow{3}{*}{520} & \multirow{3}{*}{$6 \varnothing 10$} & \multirow{3}{*}{$\varnothing 6 / 75$} & 78.25 & \multirow{3}{*}{520} & \multirow{3}{*}{520} \\
\hline M5 & & 170 & & & 35.06 & & & & & 76.01 & & \\
\hline M6 & & 170 & & & 35.17 & & & & & 79.96 & & \\
\hline$E$ & Eduardo and & 950 & \multirow{2}{*}{$4 \varnothing 14$} & \multirow{2}{*}{$\varnothing 8 / 200$} & 36.80 & \multirow{2}{*}{313} & \multirow{2}{*}{425} & \multirow{2}{*}{\multicolumn{2}{|c|}{$4 \varnothing 20 \varnothing 10 / 100$}} & 24.0 & \multirow{2}{*}{487} & \multirow{2}{*}{599} \\
\hline $\mathrm{N}$ & Fernando, 2008. & 770 & & & 27.00 & & & & & 17.8 & & \\
\hline
\end{tabular}

\section{Open Sees Numerical Models and Results}

In OpenSees, cross-sectional models of jacketed columns were created using uniaxial materials representing longitudinal steel, and unconfined, partially confined, and fully confined concrete. The cover concrete of the jacket is considered as unconfined. The confined portion of the jacket is modeled as partially confined. The concrete in the entire existing column is considered as fully confined, due to confinement provided by the jacket. As a result, the model included existing confined concrete, partially confined jacket concrete, and the unconfined cover of the jacket. Additionally, reinforcing bars in the existing column and jacket are modeled as two different materials. Confined and unconfined concrete are modeled based on Mander et al. (1988). In the OpenSees library, Concrete01 and Steel01 are used for all concrete and steel materials, respectively.

To simulate the friction or contact between the existing column and jacket, a coefficient of friction $\eta$, is applied to simulate the loss due to sliding or friction at the interface between the column and jacket. A slip coefficient equals to 1.0 means there is no loss or slip at the interface due to friction. In this study, different coefficients are used in the models to determine the slip coefficient appropriate for different interface conditions. Once the unconfined and confined concrete materials are defined, the concrete strength in the jacket is similarly reduced with $\eta$, as shown in Figure 2. Similarly, the yield strength of steel bars in the jacket is reduced by multiplying the steel strength by $\eta$. 
Lateral displacement of a reinforced concrete column is a combination of three different displacement components: flexural, longitudinal bar slip, and shear displacement (Figure 3a). The effect of slip of the longitudinal bars out of anchorage or footing causes rigid body rotation of the column and causes additional lateral displacement (Setzler \& Sezen, 2008). This additional displacement can be significant and is not considered in flexural deformation in the column. Similarly, if the detailing and amount of transverse steel are not sufficient in a column, large shear deformations are expected. Again, this shear displacement can be significant after the development of diagonal cracks and is not included in lateral flexural displacement (Sezen, 2008). In this research, most existing unretrofitted columns had insufficient column ties and therefore were likely to experience brittle shear failure. Therefore, it was critical to model and capture the contribution of shear and bar slip displacement.

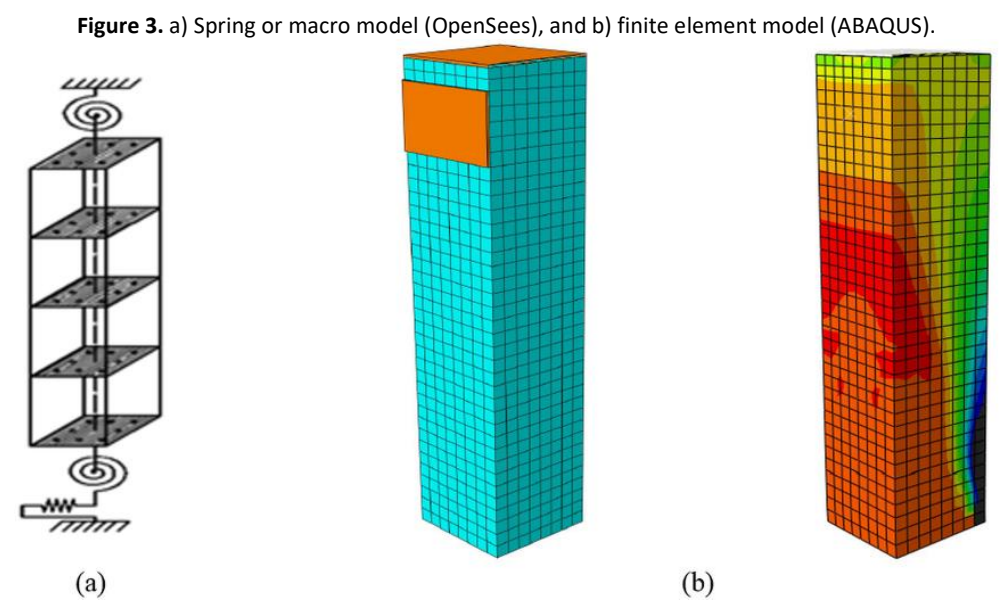

To simulate flexural displacement, distributed plasticity is considered over the height of the column, using force-beamcolumn-element in OpenSeeslibrary. Additionally, modified-Radau-hinge integration method is applied with hinge length of $L_{p}=0.08 L_{s}+0.022 F_{y j} D_{b j} L_{s}$, where $L_{s}$ is the length of the column, and $F_{y j}$ and $D_{b j}$ are yield strength and diameter of longitudinal reinforcement inside the jacket, respectively (Priestly, 1996). Slip and shear displacements are added to the flexural displacement during analysis using springs at the ends of the column (Figure 3a). In this study, shear and bar slip displacements of retrofitted columns were mostly in the linear elastic range where the stiffness of the shear spring is $G A / L$; where $G$ is the shear modulus, $A$ is the area of the section, and $L$ is the length of the column. Stiffness of the moment-slip rotation spring is determined from the section moment-curvature analysis (Setzler \& Sezen, 2008).

Julio \& Branco (2008) performed an experimental study to quantify the influence of the interface treatment on the seismic behavior of jacketed columns. They tested one column with no surface treatment (Specimen M4), roughened the interface surface of one specimen sandblasting (Specimen M5), and tested another specimen with both rough interface surface and dowels (Specimen M6).

Lateral load-displacement relationships are calculated for three specimens (M4, M5, and M6 in Figure 4) usinga macro model in OpenSees (Figure 3a). Calculated response for slip coefficient $\eta$, varying from 0.5 to 1.0 is compared with the measured response in Figure 4. A slip coefficient of as low as 0.6 seems to capture the elastic response of specimen with no treatment (M4) while a slip coefficient of 1.0 appears to represent the post-peak response of all three specimens.

Bousias et al. (2007) investigated the effectiveness of RC jacketing to improve the performance of cantilever columns with poor seismic detailing. In this research, macro models are developed in OpenSees for four specimens tested by Bousias et al. (2007). Experimental evidence was provided for the four parameters investigated to determine interface slip coefficients: 1) no treatment at interface (Specimen $Q-R C), 2$ ) roughened surface (Q-RCR), 3) dowels used (Q-RCD), and 4) both surface roughening and dowels used (Q-RCRD). The calculated lateral response of four specimens for slip coefficients varying from 0.5 to 1.0 is compared with the experimental response in Figure 5 . Overall, it can be concluded in all cases in the elastic range, the jacketed sections do not perform as fully composite, i.e., some slip is occurring at the interface. However, in the inelastic range, the effect of slip seems negligible, i.e., the slip coefficient is close to 1.0. The calculated results also show that there is more slip in the specimen with no treatment (Q-RC with slip coefficient less than 1.0) than in specimens withthe roughened surface ( $Q-R C R$ and $Q-R C R D)$ with inelastic measured response better than the simulated response with no slip $(\eta=1.0)$. 


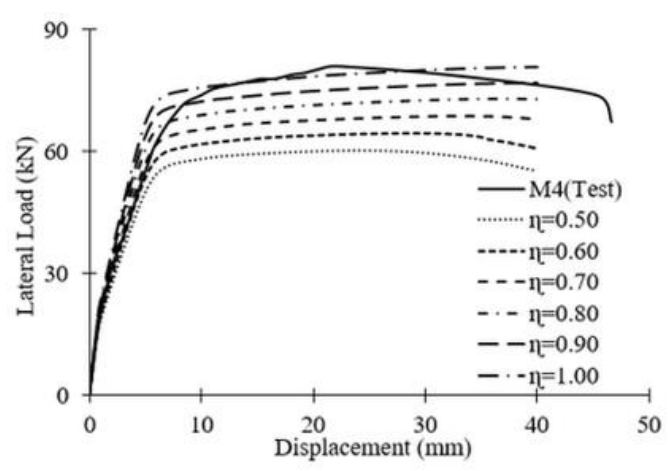

(a)

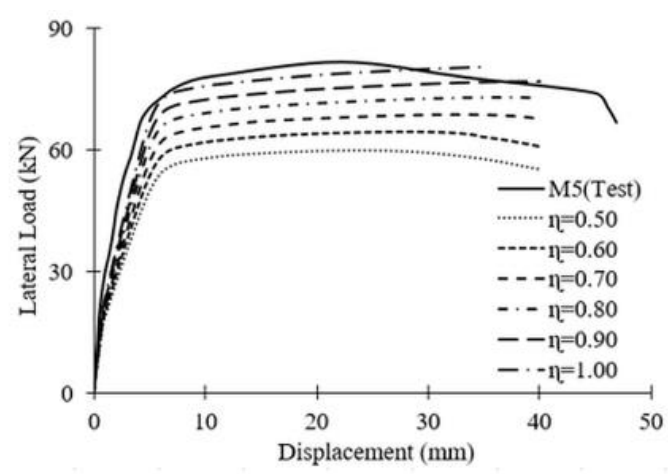

(b)

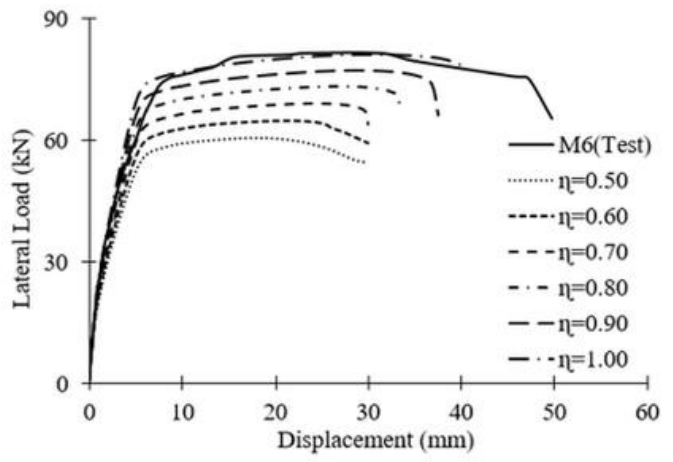

(c)

Vandoros \& Dritsos (2008) investigated the effectiveness of dowels by testing full-size concrete jacketed columns. Figure 6 compares the experimental response of two columns $\mathrm{N}$ without treatment at interface and $\mathrm{E}$ with dowels at the interface with the simulated response from macro models with varying interface slip coefficients. Unlike Bousias et al. (2007) specimens (Figure 6), limited or no interface slip is observed in Specimen N and E inthe elastic range.

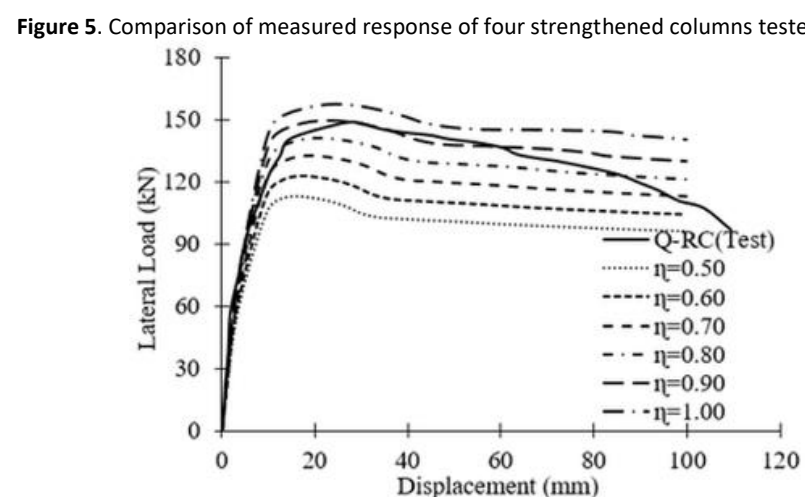

(a)

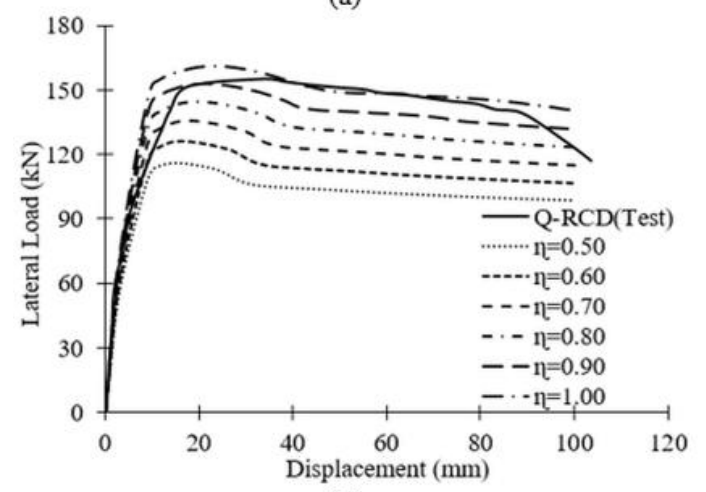

(c)

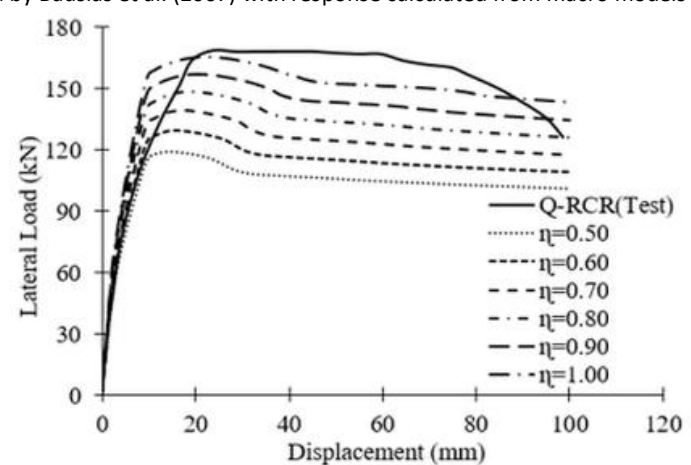

(b)

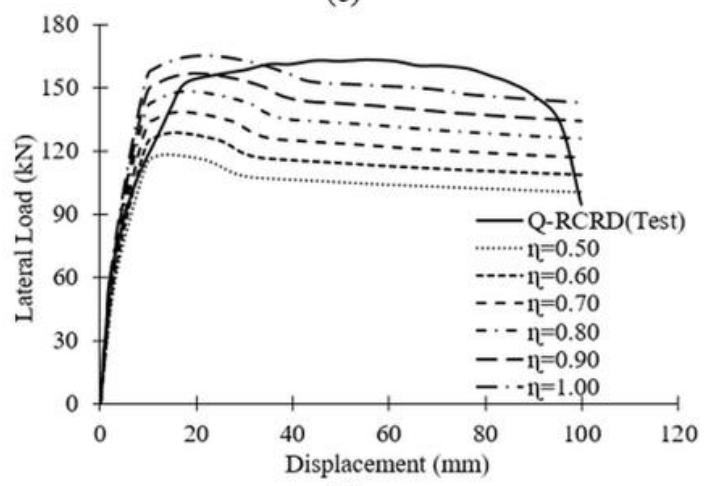

(d) 


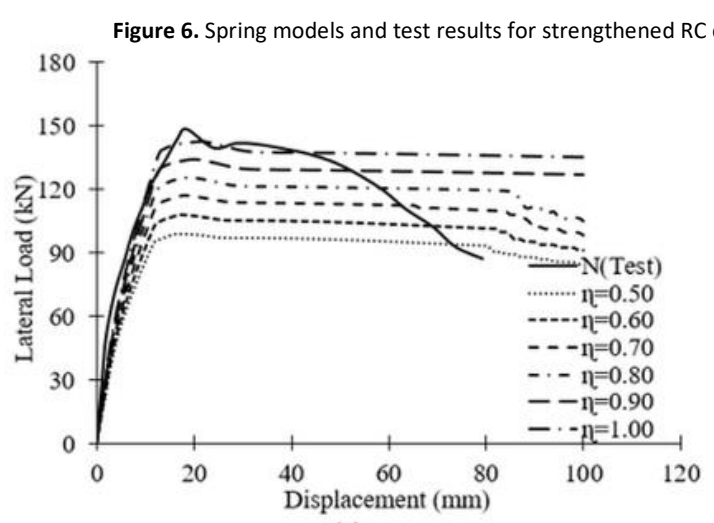

(a)

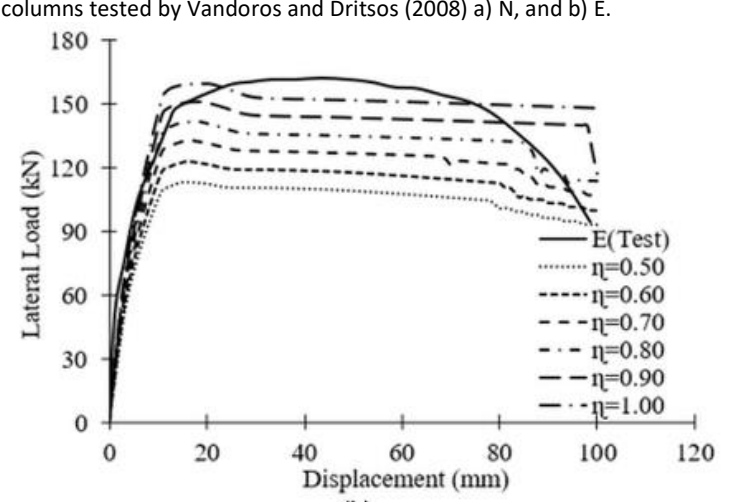

(b)

\section{ABAQUS Numerical Models and Results}

Three specimens tested by Bousias et al. (2007) are also modeled and analyzed by using ABAQUS (2020). Inelastic behavior of concrete is defined by using concrete damaged plasticity (CDP) model, which is suitable for concrete and other quasi-brittle materials. CDP is based on an isotropic damaged elasticity concept with isotropic tensile and compressive plasticity (ABAQUS, 2020; Abbas et al., 2014). The change in volume in brittle materials is generally defined as "dilation". Because of the fact that concrete is a brittle material and experiences volumetric change, it is required to define a dilation angle $(\psi)$ to represent that behavior in the CDP model. The maximum value of the dilation angle observed in literature is 56.31-degree ( $\arctan 3 / 2$ ) (ABAQUS, 2020; Abbas et al., 2014; Grassl, 2004). Since the specimens have different concrete compressive strengths for both the existing and jacketing concrete materials, $\psi$ is determined separately. The monolithic test specimen ( $\mathrm{Q}-\mathrm{RCM})$ is used to determine dilation angle of the existing concrete. In the literature, the dilation angle for RC members having a compressive strength around $30 \mathrm{MPa}$ is proposed as 30 degrees (Demir et al., 2016). It can be seen from Figure 7 that the proposed 30-degree dilation angle simulates the loaddisplacement behavior relatively accurately. Moreover, by using the determined value of $\psi$ for the core concrete, a parametric study is conducted to find a dilation angle appropriate for jacket concrete by modeling the strengthened specimen (Q-RCRD). Comparison of test and numerical results reveals that the most appropriate value of the dilation angle for the jacket concrete is 55-degree (Figure 7). The other parameters needed to be defined in the CDP model are the eccentricity which is 1.0 , the ratio of the second stress invariant on the tensile meridian, $K$, which is 0.667 and viscosity parameter, $\mu$, which is taken as 0.0001 for both core and jacket concrete as default values in ABAQUS.
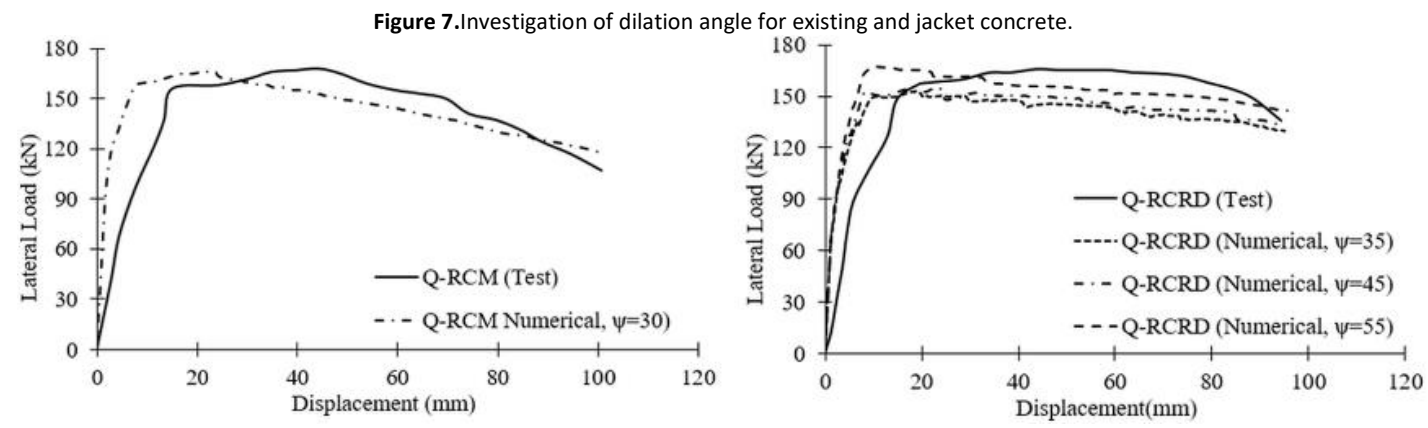

Uniaxial compressive behavior of concrete is defined in both pre- and post-peak stress range. The behavior prior to the peak strength is based on the unconfined concrete model CEB Model Code (2010). Since the post-peak behavior of concrete is mesh sensitive (Van Mier, 1986), the post-peak compression model of Vonk (1993), which accounts for the mesh size, is adopted. The tensile behavior of concrete up to peak tensile stress is assumed linear elastic. The behavior after the peak tensile stress is calculated by usingthe exponential post-peak tension softening model of Hordijk (1992). Details of the concrete material models in ABAQUS are described in Demir et al. (2016) and Farah (2017). Additionally, stress-strain relationship for reinforcing steel includes elastic and inelastic behavior including strain hardening effect.

Consistent with the experimental setup, at the loading point, steel plates are added to the FE model (Figure $3 \mathrm{~b}$ ). The axial load on the specimen is applied as a concentrated load and kept constant during analysis. Displacement-based lateral loading is applied to avoid numerical convergence issues in the FE model (Demir et al., 2016). The element type used in the FE model for concrete is eight-node linear bricks (C3D8R). Reinforcing steel is a two-node linear 3D truss element (T3D2) and is assumed fully embedded into the concrete. A parametric study is performed to determine a more accurate mesh size for the FE model. As a result, the optimum mesh size is determined to be $50 \mathrm{~mm}$ with an aspect ratio 
of 1 .

The coefficient of friction representing the interface slip between the existing column and jacket is simulated numerically by a friction coefficient using a tangential contact behavior definition, which is a surface-based contact simulation. It uses a master surface and a slave surface to simulate contact and movement of surfaces with respect to each other. The internal surface of the new concrete was defined with the master surface, and the slave surface was assigned as the old concrete component (Figure 8). In master-slave surface relation, the slave surface does not perforate the master surface. On contact of surfaces, nodes on the slave surface make contact with the closest associated nodes on the master surface and analysis is performed according to chosen tangential contact law. Moreover, a parametric study is conducted to determine the most appropriate value of $\eta$, ranging from a value of 0.0 , for no cohesion, up to 1.0 for full composite action. The FE model of specimens Q-RC, Q-RCR and Q-RCD were developed and analyzed (Figure 3b.). In Figure 9, numerical results obtained from ABAQUS and experimental data are compared. The results show that the FE models resemble the behavior of $Q-R C, Q-R C R$, and $Q-R C D$ specimens are reasonably well when the friction coefficients of $0.75,0.90$ and 0.80 are used, respectively. The proposed coefficients are summarized in Table 2 .

Figure 8. Meshed surface-based contact simulation (Van der Aa, 2014).

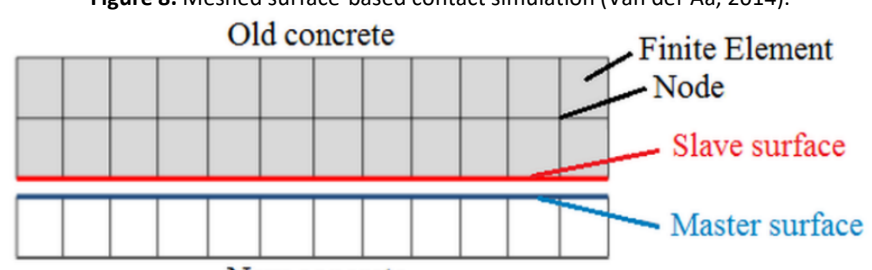

New concrete

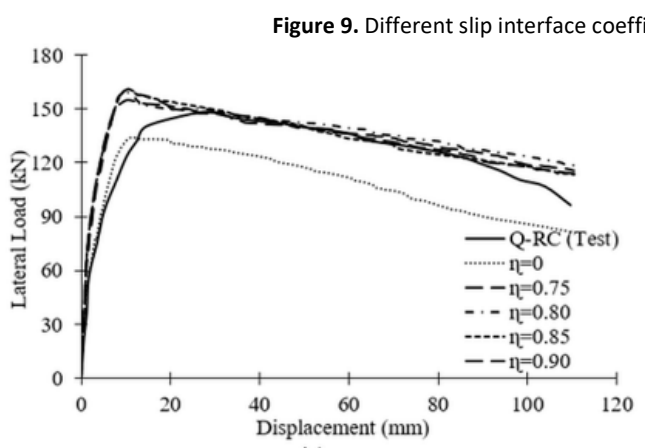

(a)

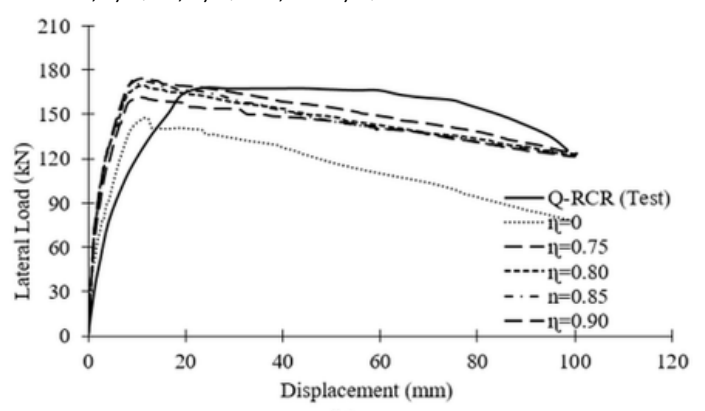

(b)

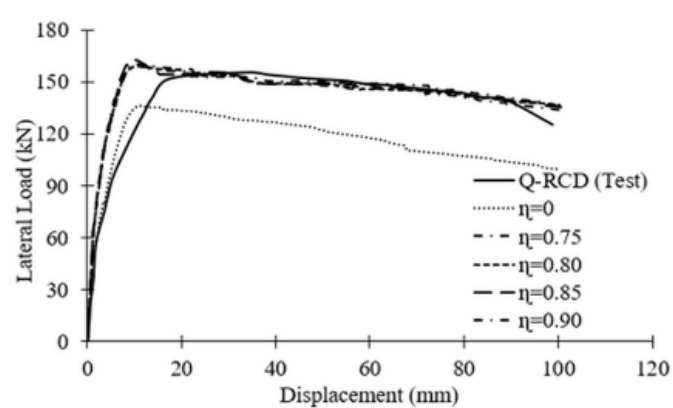

(c)

Table2. Suggested values of interface slip coefficient $(\eta)$

\begin{tabular}{cccc}
\hline \multirow{2}{*}{ Treatment } & Specimens & \multicolumn{2}{c}{ Interface Slip Coefficient $(\eta)$} \\
\cline { 3 - 4 } & & From OpenSees & From ABAQUS \\
\hline No-treatment & M4, Q-RC, N & 0.75 & 0.75 \\
Dowel & Q-RCD, E & 0.85 & 0.80 \\
Roughness & M5, Q-RCR & 0.90 & 0.90 \\
Roughness and dowel & M6, Q-RCRD & 0.90 & - \\
\hline
\end{tabular}


Retrofitting of reinforced concrete columns is an efficient way to increase stiffness, strength, and ductility of a structure to desired performance level during earthquakes or other extreme events. In this study, the factors affecting the response of reinforced concrete jacketed columns are investigated. For the column jacketing method, the main concern is the reduction in performance due to slip along with the interface between new and existing concrete. Different methods to prevent or reduce the interface slip between old and new concrete are evaluated and compared to provide guidance for engineers. A slip coefficient is proposed to represent different types of interface treatment. The proposed coefficient can be used to model the interface slip without complicated calculations.

Jacketed column performance without treatment along the interface can reasonably be expected to produce at least $70 \%$ to $75 \%$ of the behavior of an equivalent monolithic column when strength, stiffness, displacement ductility, and energy dissipation are considered. Utilization of any interface preparation method was shown to improve the performance. It can reasonably be assumed that no interface treatment corresponds to a slip coefficient of 0.75 , i.e., the strength of the untreated retrofitted section is equal to approximately $75 \%$ of the strength of the fully composite or monolithic retrofitted section. Based on numerical analyses, slip coefficients of 0.75 and 0.90 are proposed for notreatment and existing concrete surface roughening, respectively (Table 2). When dowels are used, coefficients of 0.85 and 0.80 are proposed based on OpenSees and finite element analyses, respectively. When dowels are used together with surface roughening, a coefficient of 0.90 is proposed.

The proposed slip coefficient has limitations and should be used as an approximation. The proposed slip coefficients represent the entire response of the retrofitted section includingthe elastic and nonlinear response. In addition, a limited range of concrete strengths and reinforcement configurations are used to develop the coefficients. This is mainly because there is very limited available test data, which isolates the interface condition of a jacketed section as noted throughout the study.

\section{References}

ABAQUS (2020). Dassault Systèmes, France. https://www.3ds.com/products-services/simulia/products/abaqus/abaquscae/ (accessed on June 8 , 2020).

Abbas, A.A., Mohsin, S.M.S., \& Cotsovos, D.M. (2014). Non-linear analysis of statically indeterminate SFRC columns. Structural Concrete, 15(1), 94105.https://doi.org/10.1002/suco.201300004

Bousias, S.N., Biskinis, D., Fardis, M.N., \& Spathis, A.L. (2007). Strength, stiffness, and cyclic deformation capacity of concrete jacketed members. ACI Structural Journal, 104(5), 521-531.https://doi.org/10.14359/18854

CEB Model code (2010). The fib Model Code for Concrete Structures 2010. Case Postale 88, CH-1015 Lausanne, Switzerland.

Caglar, N., Sezen, H., \& Olabi, M.N. (2019).Numerical evaluation of core concrete quality on the response of concrete jacketed columns. Revista de la Construcción, 18(2), 301-310.https://doi.org/10.7764/RDLC.18.2.301

Demir, A., Caglar, N., Ozturk, H., \& Sumer, Y. (2016). Nonlinear finite element study on the improvement of shear capacity in reinforced concrete TSection beams by an alternative diagonal shear reinforcement. Engineering Structures, 120, 158165.https://doi.org/10.1016/j.engstruct.2016.04.029

Elbakry, H.M.F., \& Tarabia, A.M. (2016). Factors affecting bond strength of RC column jackets. Alexandria Engineering Journal, 55(1), 5767.https://doi.org/10.1016/j.aej.2016.01.014

Farah, A.F. (2017). Investigation of intermediate surface of reinforced concrete jacketed columns (in Turkish) [M.Sc. Dissertation, Institute of Natural Sciences, Sakarya University]. https://tez.yok.gov.tr/UlusalTezMerkezi/TezGoster?key=q3-d9QtLoVA2OMExHSkJpdB4IFd7RLIIEprMmBub940wpdxD7CnvqufzqghPvkIr

Grassl, P. (2004). Modelling of dilation of concrete and its effect in triaxial compression. Finite Elements in Analysis and Design, 40, 1021-1033. https://doi.org/10.1016/j.finel.2003.04.002

Hordijk, D.A. (1992). Tensile and tensile fatigue behaviour of concrete - experiments, modelling and analyses. Heron, 37(1), 3-79.

Julio, E. S., Branco, F. A. B., \& Silva, V.D. (2003). Structural rehabilitation of columns with reinforced concrete jacketing. Progress in Structural Engineering and Materials, 5(1), 29-37.https://doi.org/10.1002/pse.140

Julio, E.N.B.S., Branco, F. A. B., \& Silva, V.D. (2005). Reinforced concrete jacketing-interface influence on monotonic loading response. ACI Structural Journal, 102(2), 252-257.https://doi.org/10.14359/14276

Julio, E.N.B.S., \& Branco, F. A. B. (2008).Reinforced Concrete Jacketing - Interface Influence on Cyclic Loading Response. ACl Structural Journal, 105(4), 1-7.https://doi.org/10.14359/19861

Kaliyaperumal, G., \& Sengupta, A.K. (2009). Seismic retrofit of columns in buildings for flexure using concrete jacket. ISET Journal of Earthquake Technology, 46(2), 77-107.

Mander, J.B., Priestley, J., \& Park, R. (1988). Theoretical stress-strain model for confined concrete. ASCE Journal of Structural Engineering, 114(8), 1804-1825. 
McKenna, F., Fenves, G.L., \& Scott, M.H. (2004). Open system for earthquake engineering simulation. Pacific Earthquake Engineering Research Center University of California, Berkeley. http://opensees.berkeley.edu.

Parvin, A., \& Brighton, D. (2014). FRP Composites strengthening of concrete columns under various loading conditions. Polymers, 6(4), 10401056.https://doi.org/10.3390/polym6041040

Priestley, M.J.N. (1996). Displacement-Based Seismic Assessment of Existing Reinforced Concrete Buildings. Bulletin of the New Zealand and Nationa Society for Earthquake Engineering, 29(4), 256-272.

Rodriguez, M., \& Park, R. (1994). Seismic load tests on reinforced concrete columns strengthened by jacketing. Structural Journal, $91(2), 150-159$.

Santos, P.M. D., \& Julio, E.N.B.S. (2014). Interface shear transfer on composite concrete members. ACl Structural Journal, 111(1), $113-121$.

Setzler, E.J., \& Sezen, H. (2008).Model for the Lateral Behavior of Reinforced Concrete Columns Including Shear Deformations. Earthquake Spectra, 24(2), 493-511.https://doi.org/10.1193/1.2932078

Sezen, H. (2008). Shear deformation model for reinforced concrete columns. Structural Engineering and Mechanics, $28(1)$, 39-52. https://doi.org/10.12989/sem.2008.28.1.039

Sichko, A., (2017). Review and Evaluation of Reinforced Concrete Member Retrofit Methods. [M.Sc. Dissertation, The Ohio State University]. https://etd.ohiolink.edu/!etd.send_file?accession=osu15006558558915\&disposition=inline

Sichko, A., \& Sezen, H. (2017). Review of Methods for Reinforced Concrete Column Retrofit. Fourth Conference on Smart Monitoring, Assessment and Rehabilitation of Civil Structures-SMAR 2017, Zurich, Switzerland.

Thermou, G.E., Papanikolaou, V.K., \& Kappos, A.J. (2014). Flexural behaviour of reinforced concrete jacketed columns under reversed cyclic loading. Engineering Structures, 76, 270-282.https://doi.org/10.1016/j.engstruct.2014.07.013

Tsakiris, S.A., Rousakis, T.A., \& Karabinis, A.I. (2012). Confinement effects and strain transfer in reinforced concrete jackets of different detailing for the strengthening of old-type concrete columns. 15th World Conference on Earthquake Engineering, Lisbon, Portugal.

Tsionis, G., Apostolska, R., \& Tauver, F. (2014). Seismic strengthening of RC buildings. Luxembourg: Publications Office. http://dx.publications.europa.eu/10.2788/138156.

Vardai, A. (2018). Deformation-based method for the analysis of reinforced concrete- and fiber reinforced polymer-jacketed columns subjected to axial compression. Structural Concrete, 19, 1013-1022. https://doi.org/10.1002/suco.201700019

Van der Aa, P.J. (2014). Biaxial Stresses in Steel Fibre Reinforced Concrete Modelling the Pull-Out Behaviour of a Single Steel Fibre using FEM. Faculty of Architecture Building and Planning Unit Structural DesingConcretete Structures, Eindhovenen University of Technology, Eindhovenen.

Van Mier, J. (1986). Multiaxial Strain-Softening of Concrete. Materials and Structures (RILEM), 19(111), 179-200.

Vandoros, K. G., \& Dritsos, S.E. (2008). Concrete jacket construction detail effectiveness when strengthening RC columns. Construction and Building Materials, 22(3), 264-276.https://doi.org/10.1016/j.conbuildmat.2006.08.019

Vandoros, K.G. \& Dritsos, S.E. (2006). Interface treatment in shotcrete jacketing of reinforced concrete columns to improve seismic performance. Structural Engineering and Mechanics, 23(1), 43-61.https://doi.org/10.12989/sem.2006.23.1.043

Vonk, R.A. (1993). A micromechanical investigation of softening of concrete loaded in compression. Heron, 38(3), 3-94. 